toren ab. Aber wir haben Pollenkörner gefunden, die so spezifisch nur in der Wohnung vorkamen. Das heißt, ja, prinzipiell geht es. Es gehört natürlich ein bisschen Glück dazu, aber es ist immer einen Versuch wert.

\section{MMW: Wann werden Sie von der Kriminalpolizei hinzugezogen?}

Weber: In der Regel bei Morden, da ist nichts zu teuer. Wir werden ungefähr zweimal im Jahr hinzugezogen. In Österreich haben wir das Glück, dass sich die ermittelnden Behörden für Pollen interessieren und wir auch in Tatortschulungen integriert sind.

Interview: Dr. Beate Schumacher

\section{Pollenkörner führten zum Versteck der Leiche}

Der weltweit erste Fall, bei dem die Pollenanalyse zur Aufklärung eines Verbrechens beigetragen hat, hat sich 1959/60 in Österreich zugetragen. Ein Mann wurde als vermisst gemeldet. Er war zuletzt mit einem Freund gesehen worden, der polizeibekannt war und sofort unter Verdacht geriet. Bei der Durchsuchung seiner Wohnung fand man ein großes Waffenarsenal, und der Mann gestand, dass er seinem Freund eine Waffe gezeigt und sich dabei versehentlich ein tödlicher Schuss gelöst habe.

Zum Versteck des Toten machte er wechselnde Angaben, aber an keinem der Orte wurde die Leiche gefunden. Der Wiener Paläobotaniker Prof. Wilhelm Klaus, einer meiner Lehrer, hatte dann die Idee, Schuhe und Kleidung des Verdächtigen auf Pollen zu untersuchen. Die Pollenkörner, die er fand, waren typisch für ein Auengebiet. Außerdem hatte Klaus das Glück, ein fossiles Hickory-Nuss-Pollenkorn zu finden, von dem er wusste, dass es nur im Nordwesten von Wien in der Au bei Spillern vorkommt.

Als man dem Verdächtigen auf den Kopf zusagte, dass er die Leiche dort begraben habe, war der so schockiert, dass er die Kriminalpolizei hinführte. Das Opfer hatte ein Schussloch genau zwischen den Augen. Der Täter wurde deshalb wegen Mordes verurteilt.

Prof. Martina Weber

\title{
Exogen-allergische Alveolitis Tödliche Pilze aus dem Dudelsack
}

\author{
Musiker sollten Blasinstrumente öfter mal gründlich desinfizieren - \\ sonst können sich darin allergene Pilze vermehren. Einem Briten \\ wurde dies zum Verhängnis.
}

_ Als Ärzte um Dr. Jenny King den Mann im September 2014 in die Klinik in Wythenshawe nahe Manchester aufnahmen, war es schon zu spät: Die Lungenfunktion verschlechterte sich zusehends, nach sechs Wochen starb der Patient. Als Ursache erkannten sie eine akute Exazerbation einer Hypersensitivitätspneumonitis. Was jedoch die Erkrankung auslöste, war zunächst unklar.

\section{Mysteriöse Allergenquelle}

Die Leidensgeschichte des Mannes begann sieben Jahre zuvor mit trockenem Husten und progressiver Kurzatmigkeit. Bereits fünf Jahre vor seinem Tod erkannten die Ärzte anhand der Symptome und durch hochauflösende CT-Aufnahmen eine exogen-allergische Alveolitis als Ursache der Beschwerden, konnten jedoch die Allergenquelle nicht finden. In der Wohnung des Mannes gab es keinen Schimmelpilzbefall, Wasserschäden waren nicht bekannt und mit Vögeln hatte der Brite keinen Kontakt. Dass er täglich Dudelsack spielte, hatte er wohl angegeben, doch die Ärzte schöpften zunächst keinen Verdacht.

Trotz immunsuppressiver Therapie verschlechterten sich seine Lungenfunktion und seine körperliche Leistungsfähigkeit immer mehr - mit einer Ausnahme: 2011 reiste er für drei Monate ohne Dudelsack nach Australien, in dieser Zeit verbesserte sich sein Zustand.

Wieder zuhause ging es jedoch weiter rapide bergab. Die forcierte exspiratorische Vitalkapazität (FVC) sank auf 34\%. Er konnte gerade noch 20 Meter ohne Pausen laufen. Er blies jedoch weiterhin jeden Tag auf seinem Dudelsack.

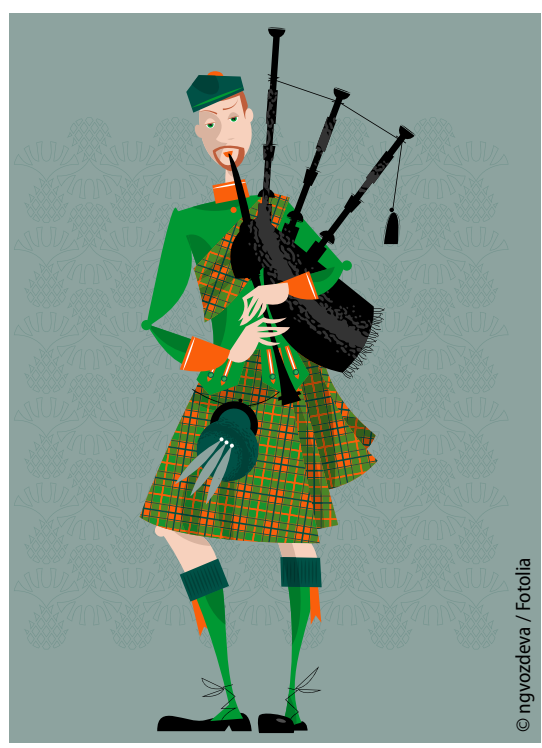

Ist der Sack sauber?

\section{Bunter Pilzmix im Dudelsack}

Erst während seines finalen Klinikaufenthalts nahmen die Ärzte den Dudelsack genauer unter die Lupe und legten Kulturen aus Abstrichen von Mundstück, Pfeifen und Sack an. Praktisch überall fanden sie diverse, zum Teil hochallergene Pilze. Einige davon waren auch schon bei anderen Patienten als Auslöser einer exogen-allergischen Alveolitis aufgetreten.

Die Ärzte fanden in der Literatur weitere Fälle solcher Erkrankungen bei Blasmusikern. Sie empfehlen Bläsern deshalb, regelmäßig ihre Instrumente zu desinfizieren. Außerdem sollte man Alveolitis-Patienten öfter nach ihren Hobbies fragen.

- mut

- King J et al. Thorax 2016, online 22. August doi: 10.1136/thoraxjnl-2016-208751 